\section{TIME PERSPECTIVES IN SCIENCE*}

\author{
By Prof. A. E. HEATH \\ University College, Swansea
}

$\mathrm{O}$ $\mathrm{NE}$ of the best ways of broadening our minds, and clearing ourselves of local limitations and prejudices, is travel in space. Travel in time is equally effective, and cheaper. It takes us out of our narrow setting and restores our sense of proportion by confronting our parochialisms with those of other peoples and periods.

'This is true in science as in other human concorns. Here, too, are fashions and unconscious temporal shortsightedness. Even inside the special sciences themselves, historical considerations are important. Although "any science which hesitates to forget its histiory is lost", it can equally be asserted that any science which does not relate itself to its historical background runs the risk of sterility. Its origins, as specialization increases, may be lost sight of ; and dead ends appear in developing thought as in the evolution of living creatures. Its connexions with cognate studies tend to be overlooked, and fruitful possibilities of investigation, produced by a sort of cross-fertilization, neglected. The very meaning of its terms may be too narrowly conceived, as Huxley hinted when he said, "The parallax of time helps us to the true position of scieritific conceptions as the parallax of space to that of a star".

It is, however, when we think of science as an instrument for furthering human ends that the full importance of its history comes to light. Viewed in its wider setting, we can see that man has, now, accumulated more knowledge than he can apply. This is sometimes spoken of as a failure in moral insight. If that were the correct diagnosis it would be a very curious thing, considering the many centuries of concentration by saints and sages on moral issues. I prefer to put the emphasis elsewhere. I should call it a failure of nerve. Wisdom is not knowledge only, but knowledge plus plasticity. We lose our nerve when we fail to adapt ourselves to change.

It is not commonly realized how modern the modern temper is. By applying a balanced form of reflexion (in which a passion for brute fact is combined with capacity for generalization) to every department of human life, we have achieved, in the last three centuries, a picture of the world which is staggeringly different from those cosmologies within the framework of which our institutions have been built. The step from Dante's world to that of Einstein and Freud has been taken much too briskly for us to keep pace. The new world is just as wonderful as the old, providing the fullest scope for philosopher, poet and prophet to work their synthesizing genius upon. But this enterprise has scarcely yet begun. We have been too much occupied with piecemead adjustments to the disturbing political and economic developments which have followed on the heels of intellectual change. Consequently we have been forced to carry over our old mental furniture (to amplify an image of the late J. W. N. Sullivan's) into new settings for which it is ill-suited. Our first dwelling, at the beginning of this period of three hundred years, was the neat, cosy, friendly world of Dante in which we could live confidently, regarding Nature as subservient to our human purposes and destiny. From that we passed

- Substance of a lecture at the British Social Hygiene Council Summer School at Eton Oollege, August 1943. on to the wider world, big and orderly but detached, of the Newtonian system; and now, in our own day, we are translated to a vast, though bounded, universe -so bare and empty that the mind reels at its immensities and cold unconcern. Throughout all these changes we have carried with us the same homely mental furniture that served us in our first dwelling-place. It is as though we began by making shift with the contents of a small cottage when we moved into a lordly mansion in Park Lane. That would be bad enough. But the further move is like transplanting our little belongings to the middle of Salisbury Plain.

It is hard enough for us to readjust our attitude to the world outside us--to the macrocosm : but when we turn our attention inwards to the microcosm, to the little world of man and his social relationships, the difficulties increase enormously. For in this realm, too, we are carrying into the new era, with even greater tenacity, mental presuppositions about all sorts of things-about nationality, about economic realities, about sex and family-which served us in the past but may now, in altered conditions, bring ruin upon us. It is not a question of destroying our mental furniture: we cannot hope to start afresh with new minds and bodies. Our. problem is, rather, how best to reshape and supplement what we already have. But before such refashioning can be begun, we have to rid ourselves of the superstitious terrors which now hinder us, in every department of social affairs, from organizing our civilization so as best to

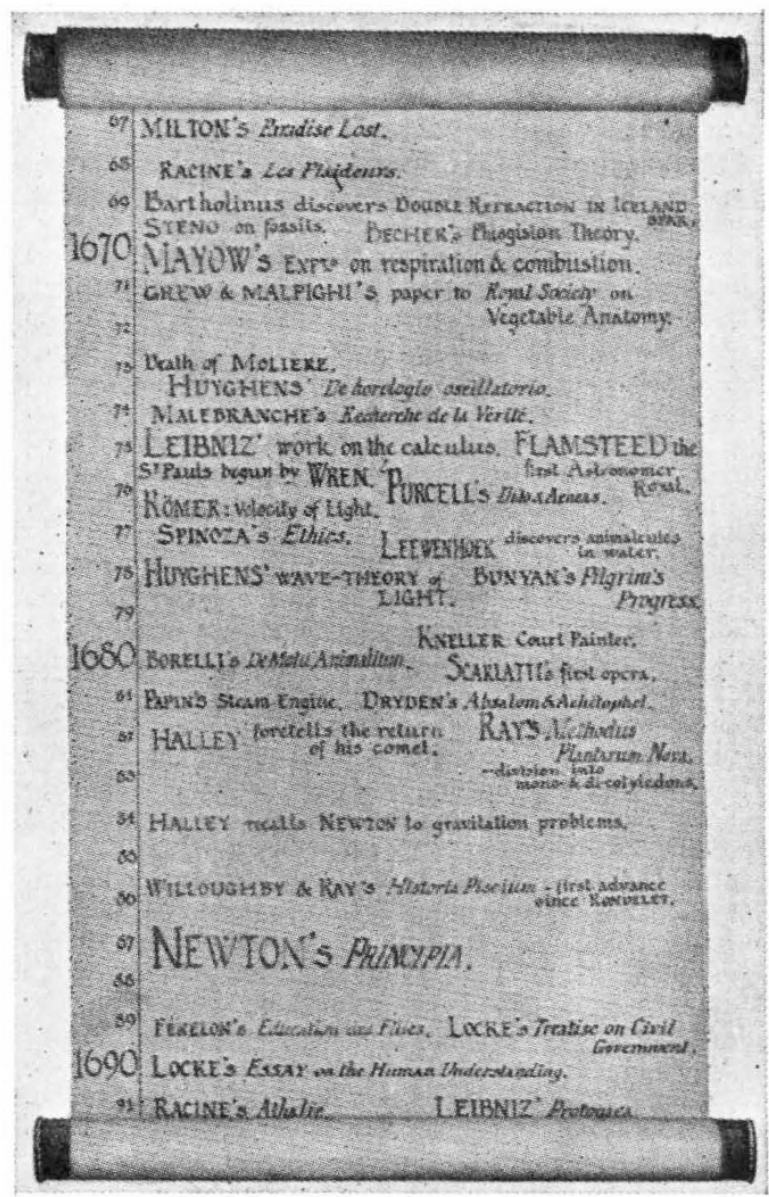

Fig. 1. 
serve the ends of human happiness. Scientific knowledge does not of itself free us. "Learning", as Santayana has remarked, "does not liberate men from superstition when their souls are cowed and perplexed". To the bread of knowledge must be added the salt of intelligence by which I mean the power of plastic adjustment to change. That is the touch. stone by which the future of man on this planet can be gauged, as it has been the test for every other animal throughout geological time: Can he adapt himself quickly enough to changes in his environing conditions?

Our social and cultural disharmonies are thus largely the product of our failing to acclimatize ourselves to modern cosmologies. There is a disastrous divorce between what we know and what we feel : and to this our nerveless grasp upon our destiny is due. The prime essential for adaptation is a synthesis of the sciences of life with the sciences of the physical world. We shall need to fit our studies into a wider and more inclusive perspective. If we are to have a technocratic order it must transcend its engineering stage and become a biotechnocracy.

In the achievement of this, historical considerations are paramount, and they need not be.complicated. We have the knowledge. It only needs to be effectively geared. Even such ordinary things as chronological charts provide admirable means of travel through time. These have two useful qualities. They help us, in the first place, to grasp the connexion between events in a given period; and in the second place, to set the period itself in its proper timerelation to others.

As an example of the first, there is reproduced in Fig. I a small portion of a long chronological chart I made partly for my own amusement and partly hecause I wanted to get an idea of the historical background of scientific work in different ages. I therefore put down the names of men of science and their discoveries, varying the size of the lettering with the importance of the man or his work, in red script: and then entered on the chart, in black, events in social and cultural history. I was astonished to find how illuminating a bare chronological series of events, set out in this way on a uniform time-scale, could be. In the portion of the chart here illustrated it is possible, for example, to see at a glance that the seventeenth century was not merely the age of mechanics in its narrow sense; that characteristic is reflected also in other branches of human activity. Besides the names of Newton and Leibniz we see that of Borelli, whose book "De Motu Animalium" is the first application of mechanical ideas to the structure of the human body ; of Spinoza, whose "Ethics" was written, under the influence of the prevailing mood of the time, in "a geometrical manner" ; of Scarlatti, who did not scorn technical experiment as a basis for composition. The whole thing hangs together.

The complete chart, upon which the sixteenth century is also entered, is several yards long, and can be moved on its rollers so that it can be looked over in a few minutes. History unrolled in this manner, by the yard, enables us to eatch other unities. It becomes clear, for example, that each age has its own peculiar scientific flavour. Thus there is a certain disconnectedness in the scientific entries in the sixteenth century: it was more like the spasmodic inventiveness which still stands for 'science' in many minds. When we turn to the seventeenth century, we notice at once instances of inter-

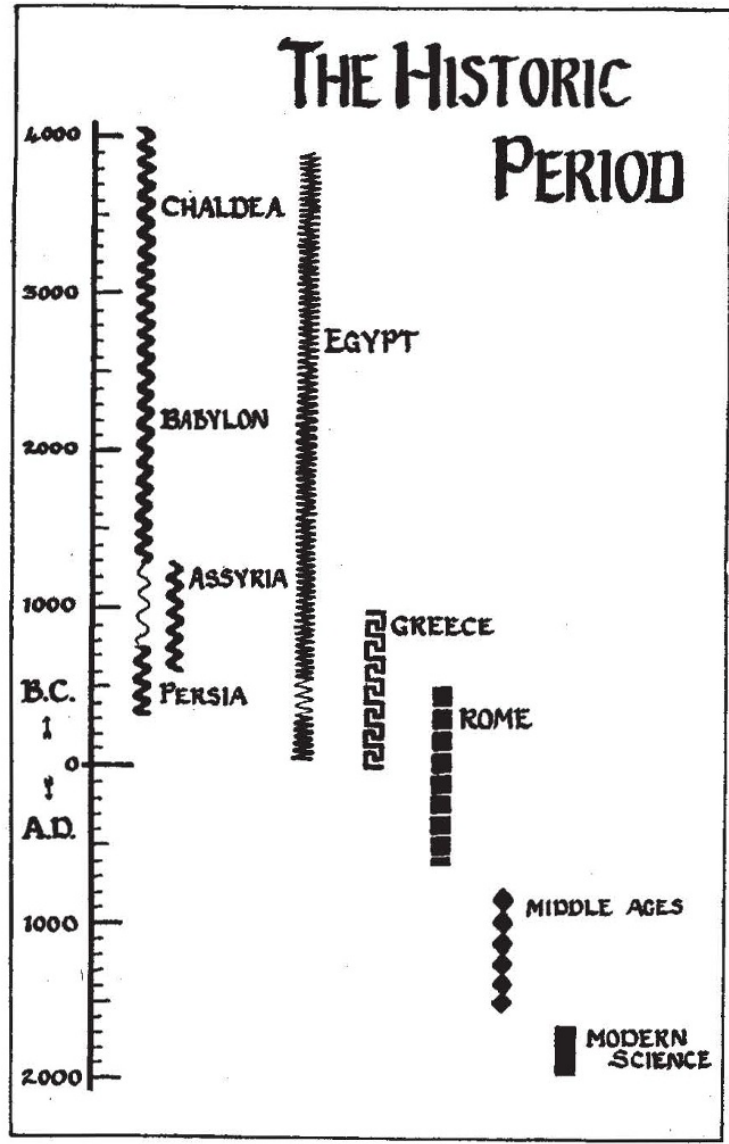

Fig. 2.

connexion and co-operation. Results in one field were used in another-as when Galileo, hearing of the invention of the telescope, constructed one, but turned it immediately to astronomical use; or when Pascal tried the effect of carrying the Torricellian tube up a mountain to see if the lessened weight of the atmosphere would be registered. The increasingly co-operative and cumulative character of science in the seventeenth century was brought out also by the appearance on the chart of the date of foundation of all the great European academies of science. This characteristic makes one realize, as nothing else can, the importance of this century for future ages ; since without it the ground could not have been cleared of the age-long accumulation of systems which cumbered it. Individual men working in isolation could not have coped with the enormous labour of putting such systems to the test of fact.

Another way in which the mere setting of events in order provided illumination was in the chart of the same kind which I made for the Middle Ages, and from which it became clear that the only scientific work in the earlier centuries of this period was under Arabic names. My own school-history had given me no hint of the fact that for several centuries the torch of Western civilization was in Mohammedan hands. Here, suddenly, I was brought face to face with it. The scraps of knowledge I possessed about the beautiful, but mysteriously early, Moorish architecture in Spain; about Toledo steel; about the Arabic origin of words like alchemy and algebra; about the sources of our knowledge of classical 
antiquity in Arabic translations-all these fell together like the parts of a jig-saw puzzle. It was in this fashion that the detailed charts of the beginnings of modern science brought out unsuspected relationships between events and gave them new significance.

The second use of chronological charts, I said earlier, is to throw any given period taken as a whole into its wider relationships with others. For this the construction of time-lines is invaluable. If we wish, for example, to see how the modern period is related in time to the ancient world, and to the great empires which came before, we can represent them by a series of parallel lines, drawn to a common scale on a single chart. An example is shown in Fig. 2. Here is the picture of the brief period of modern scientific thought set in relation to its forerunners. It was fashionable some years ago in philosophical circles to talk about the bankruptcy of science. All that is necessary in reply is to take a reassuring glance at this chart; the balanced objective method of viewed as biological processes : not like the mechanical changing of the harness of a horse, but more like a reptile shedding its skin : a delicate business, not lightly undertaken. A new biotechnology, in making this explicit, will help to free us from the exaggerated fears which tempt us to purchase security at the price of servitude.

Even broader relationships of our modern period to earlier ages can be illustrated if we extend the range of our charts by making the scale successively smaller, a method used with great effect by Olaf Stapledon in one of his books. A series of time-lines constructed in this way is shown in Fig. 3. In the first of these, in which each unit of length represents a thousand years, we seo the whole historical period dwarfed to insignificance in comparison with the range of man's neolithic civilization. In No. 2, where each unit is ten thousand years, this in turn is dwarfed by the vast length of the palmolithic or old stone age of man, before he had created anything but the crudest of stone weapons or developed an

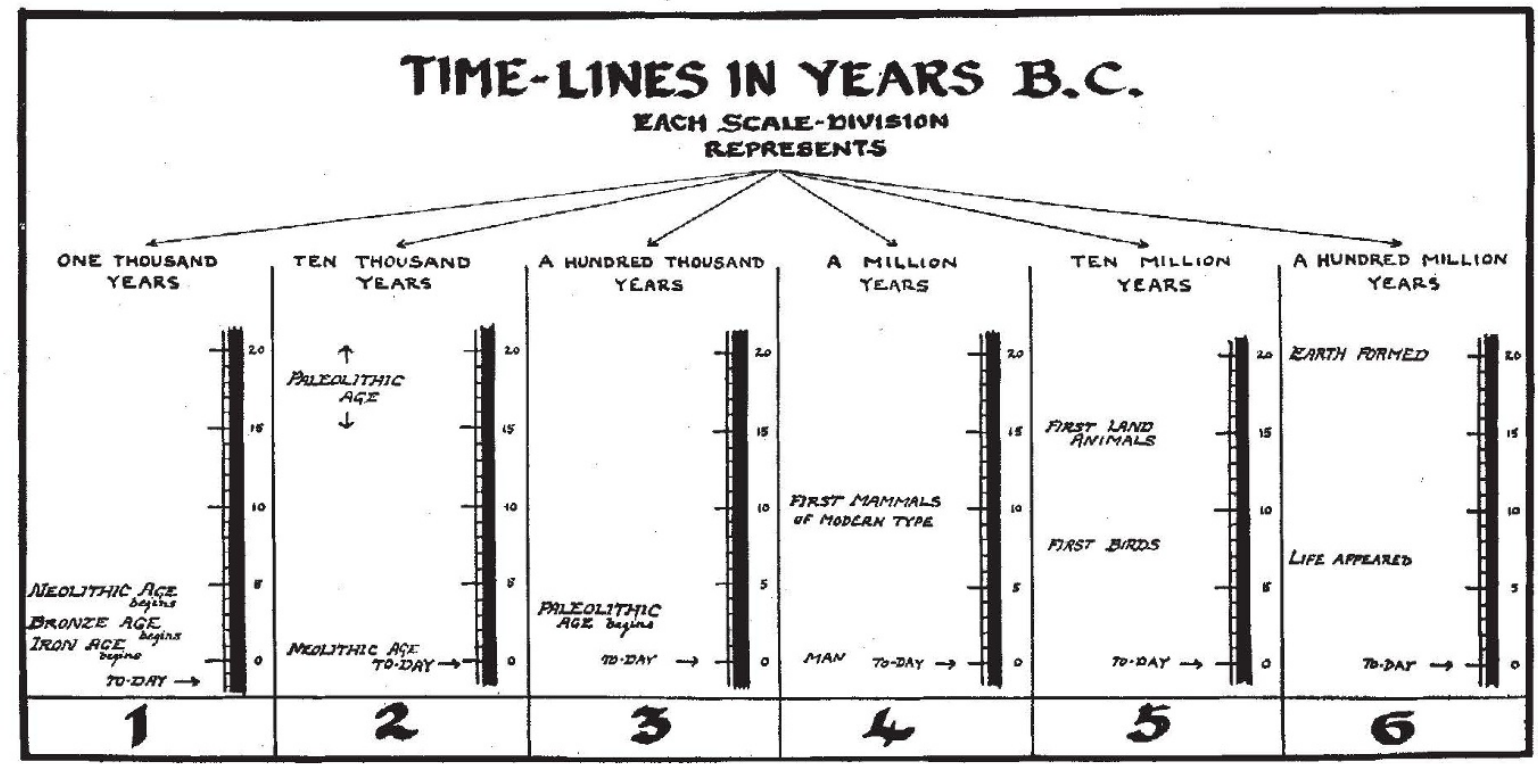

Fig. 3.

reflexion which we call science is too recent an acquisition for us to pass final judgment on it. It is interesting to notice, on this chart, the comparatively great length of line representing the stable early empires. It reminds us of the important fact that man has been able to build for himself solid, and even partially urban (though unprogressive), civilizations, on the basis of a rigid fibre of lawunchanging as the laws of the Medes and Persiansin which the subordination of the individual to society is far greater than in our time. Perhaps man was more docile in earlier ages, before his reflective awakening to complete social self-consciousness in ancient Greece. In our day we are forced to stress the character of change, because we live in a time of change and have much leeway to make up. But we must never forget that there have been many civilizations before our own; and that some of these, as in China and the Elast, can reach a high cultural level of an unchanging kind if they are content to remain mainly agricultural. For living renewal, cultural changes are necessary : but they must be agricultural society. The palæolithic period indeed runs over to No. 3. We are thus enabled to comprehend the vitally important time-relation between man's hunting, agricultural and modern forms of social organization. It probably took him a quarter of a million years to create a society out of the hunting pack ; and some five thousand years more to produce an ordered agricultural community. Building on his newly acquired powers over natural forces it should, Prof. J. B. S. Haldane has not too hopefully suggested, take him a shorter time to evolve a stable industrial society. Perhaps we shall be more hopeful if we remind ourselves how brief, in comparison with his whole life, is the modern period. If, now, we extend our scales still further we have on No. 4 the appearance of mammals of modern type ; on No. 5 birds and the first land animals; and on No. 6 there comes at last into our ken the beginning of the earth itself.

But the beginnings of things remind us inevitably of ends. Our imagination, once started, may range forward into the far distant future : and we may pass beyond these discussions of the immediate problems 
of human civilization to wonder about their ultimate end in the death of the solar system.

We have been looking at man in the light of time. It may be felt that the tale is incomplete unless we also try, with Spinoza, to view him "in the light of eternity". Many will be able to face this last ordeal hopefully because they are convinced that, whatever may be the final fate of our world, there is an eternal place for man in the universe. I myself have no such conviction. Yet I do not despair-as some unhappy folk do, who have not the support of faith. To them I would offer the consolation of another journey through time under the guidance of Sir James Jeans. Imagine a clock which ticks not seconds but years. Its minutes will be a man's three score years. By this clock it was only seventy years ago that the earth was formed; only three days since man appeared; and only five minutes from the beginnings of balanced reflection. On this scale the astronomer gives man, at a very low estimate, another seventy years to run his course upon this planet. Mankind is thus, by this reckoning, a three-days old baby, born into a house seventy years old. He has only in the last few minutes woken up to a first awareness of his surroundings, and has the prospect of seventy years of life before him. There are moments in the lives of men, even of young men, when they fret at the passing of time. Like the Shropshire Lad contemplating the loveliness of cherry-blossom in spring, they murmur regretfully : "Of my three score years and ten, Twenty will not come again". But it is only a passing mood at twenty. It should not be a mood at all for the new-born infant.

There is another lesson to be learned from this way of viewing the human race in time. The baby is not likely to be concerned at the briefness of its life : but it is, so modern psychologists tell us, likely to be longing inarticulately for a return to the simpler conditions of dependence which it enjoyed before birth. That mood, so beautifully expressed in another of A. E. Housman's poems beginning, "Be still my soul, be still; the arms you bear are brittle", can carry forward into later life. Our infantilisms in social affairs bear witness to this. The danger which faces the human race in its present infant form is not hopelessness at the prospect of ultimate extinction, but despair at the harsh complexities of life which it is being forced to face. The real choice before us is between despairing refusal to grow up and its only alternative-resolute advance to maturity along the path of clear-eyed reflection.

\section{STUDIES OF TWINS IN THE SOCIAL SCIENCES}

\section{BY JOAN C. SQUIRES}

T

WINS, together with other multiple human births, have always been of interest to the society of which they are members. In primitive communities, twins are regarded as being possessed of supernatural powers, which may or may not prove propitious to the group. Within the last seventy years, social scientists have made use of twins in an effort to solve the vexed question of the respective influences of heredity and environment on the formation of human character and physique.

There are two distinct types of twins. Dizygotic or fraternal twins are the product of two separately fertilized ova, which are independent from the moment of conception. 'Twins of this type have a common pre-natal and post-natal environment, but apart from these similarities, the latter enhanced by the fact that they are of the same age and thus subject to common experience, they appear to bear no more resemblance to one another than to other siblings. They may be of the same or opposite sex. On the other hand, monozygotic or identical twins are the product of one ovum, which, after fertilization, splits into two-these twins possess the same genetic constitution and are always of the same sex. Criteria for diagnosing monozygotic twins include a striking similarity in general appearance, which results in their being mistaken for one another, such as the possession of identical hair colour and texture, eye colour and pigment pattern on the iris-and a stronger cross than internal resemblance in most of the details of the finger and palm patterns - that is, the right hand of one twin resembles more closely the right hand of the other than his own left hand. It must be made clear that the term 'identical' can, in one respect, be misleading, since, as Prof. Newman points out, no two persons are born exactly alike - but he attributes the slight physical differences of monozygotic twins at birth to the inferior pre-natal position of one to the other, and the consequent decrease in blood supply ${ }^{2}$. The principle that all men are born equal is a political belief rather than a biological truth. The fact, however, that identical twins have the same genetic constitution, while fraternal twins differ in this respect within the limitations of the parental genes, makes the problem of heredity-environment influence easier to solve, since by series of control experiments the approximate values of these two factors can be ascertained.

Francis Galton was the first person to make a study of this problem. $\mathrm{He}$ examined thirty-five pairs of similar and twenty pairs of dissimilar twins, with the object of determining whether or not similar twins became unlike as a result of difference in environment, and whether dissimilar twins became more alike when living in the same environment. The segregation into similar and dissimilar was not as scientific as it would be were the experiment carried out to-day, but it approximated roughly to a division between identical and fraternal twins. Galton relied for his evidence on reports of the twins made by near relations or friends. These anecdotal sources of information have now been rejected in favour of control experiments. He was concerned more with a study of the physical than the mental characteristics. Both members of seven pairs of similar twins suffered from the same physical ailment, and there were two cases of similar insanity. Eleven pairs reported similarity in association of ideas-for example, one twin would begin a sentence and the other would end it. In nineteen cases of similar twins, however, there were marked differences in dis. position, but these were ultimately attributable to illness or accident. This led Galton to the conclusion that: "we may, therefore, broadly conclude that the only eircumstances within the range of those by which persons of similar conditions of life are affected, that is, capable of producing a marked effect on the character of adults, is illness or some accident which causes physical infirmity. The impression that all this leaves on the mind is one of some wonder whether nurture can do anything at all beyond give instruction in professional training. There is no escape from the conclusion that nature prevails enormously over 